\title{
Produção de biotensoativos a partir de resíduos de óleos e gorduras
}

\author{
Fats and oils wastes as substrates for biosurfactant production
}

\section{Siddhartha Georges Valadares Almeida de Oliveira COSTA¹, Márcia NITSCHKE², Jonas CONTIERO ${ }^{1 *}$}

\section{Resumo}

O presente trabalho visou a seleção de microrganismos com capacidade de produzir biotensoativos a partir de resíduos de óleos e gorduras gerados em restaurantes e indústrias alimentícias. Borra de soja, gordura de frango, gordura vegetal hidrogenada e óleo de soja usado em frituras foram estudados como fonte de carbono. Os isolados LMI 6c e LMI 7a, ambos pertencentes ao gênero Pseudomonas, foram selecionados como potenciais produtores de biotensoativos. Dentre os resíduos propostos, a borra de soja foi considerada o melhor substrato, gerando 9,69 g. $\mathrm{L}^{-1}$ de ramnolipídios e uma tensão superficial de $31 \mathrm{mN} / \mathrm{m}$.

Palavras-chave: biossurfatantes; biotensoativos; ramnolipídios; Pseudomonas sp.; resíduos oleosos.

\begin{abstract}
The purpose of this study was to select microorganisms that were able to produce biosurfactants from fats and oils wastes generated by the food industry and restaurants. Soybean soapstock, chicken fat, hydrogenated vegetable fat and soybean frying oil were evaluated as alternative substrates. Pseudomonas sp. isolates LMI 6c and LMI 7a showed a capacity to utilize the substrates and to produce rhamnolipid surfactants. Soybean soapstock was considered the best substrate, generating 9.69 g. $\mathrm{L}^{-1}$ of rhamnolipids and a surface tension of $31 \mathrm{mN} / \mathrm{m}$.

Keywords: biosurfactants; rhamnolipids; Pseudomonas sp.; oil wastes.
\end{abstract}

\section{Introdução}

Compostos de origem microbiana que exibem propriedades surfatantes, isto é, reduzem a tensão superficial e interfacial, além de apresentarem capacidade emulsificante, são conhecidos como biossurfatantes ou biotensoativos. Os biossurfatantes são classificados de acordo com a sua composição química e sua origem microbiana, e os microrganismos produtores se distribuem em diversos gêneros, em sua maioria bactérias. As principais classes de biossurfatantes incluem: glicolipídios, lipopeptídios e lipoproteínas, fosfolipídios e ácidos graxos, surfatantes poliméricos e surfatantes particulados (CAMEOTRA; MAKKAR, 1998).

A maior vantagem dos biossurfatantes quando comparados aos surfatantes sintéticos reside na sua diversidade estrutural, baixa toxicidade e biodegradabilidade. Devido a essas propriedades podem ser usados para diversas aplicações que se estendem desde a biorremediação de poluentes, até a indústria de alimentos, farmacêutica e cosmética (COSTA et al., 2006; VATER, 1986).

Os biotensoativos podem ser sintetizados a partir de substratos renováveis (açúcares, óleos vegetais e glicerol) e possuem grande diversidade química, possibilitando aplicações específicas para cada caso particular. Outra vantagem dos biossurfatantes reside no fato de serem compostos que não são derivados de petróleo, fator importante na medida em que os preços do petróleo aumentam (DESAI; BANAT, 1997).
Apesar das vantagens apresentadas, os biossurfatantes não são amplamente utilizados pelas indústrias devido ao alto custo de produção, associado à baixa produtividade e ao uso de substratos caros. Uma possível estratégia para reduzir os custos da produção seria o uso de substratos alternativos, como os resíduos agroindustriais ou de indústrias alimentícias, que geralmente contêm altos níveis de carboidratos ou lipídios necessários para a biossíntese de biossurfatantes (BANAT; MAKKAR; CAMEOTRA, 2000). Além disto, o uso de resíduos contribui para a redução da poluição ambiental e para a valorização econômica destes produtos. O uso de substratos alternativos como borra oleosa, óleos usados, melaço de cana, resíduos do processamento de queijo, batata e mandioca, são alguns exemplos de resíduos e subprodutos com potencialidade para produção de biotensoativos (ABALOS et al., 2001; COSTA et al., 2006; HABA et al., 2000; NITSCHKE et al., 2005; NITSCHKE; COSTA, 2007; VAN HAMME; SINGH; WARD, 2006).

Bactérias pertencentes ao gênero Pseudomonas são capazes de sintetizar biossurfatantes conhecidos como ramnolipídios, que estruturalmente são glicolipídios contendo ácidos graxos ligados a moléculas de ramnose (NITSCHKE; COSTA; CONTIERO, 2005). Os ramnolipídios são considerados como a classe de biotensoativos mais promissores em termos de produção industrial, pelas suas características físico-químicas e biológicas distintas, e por serem obtidos em concentrações

Recebido para publicação em 11/5/2006

Aceito para publicação em 17/12/2007 (001750)

Laboratório de Microbiologia Industrial, Departamento de Bioquímica e Microbiologia, Instituto de Biociências de Rio Claro, Universidade Estadual Paulista - UNESP,

Av. 24A 1515, CP 190, CEP 13506-900, Rio Claro-SP, Brasil,E-mail: jconti@rc.unesp.br

2 Processamento Térmico de Alimentos, Instituto de Química de São Carlos, Universidade de São Paulo - USP, Av. Trabalhador São Carlense 400, CP 780, CEP 13560-970,

Sao Carlos - SP, Brasil, E-mail: nitschke@iqsc.usp.br

${ }^{*}$ A quem a correspondência deve ser enviada 
superiores aos outros biossurfatantes, o que contribui para a difusão do uso destes compostos, especialmente em situações onde o benefício da aplicação supera os custos de produção.

Este trabalho teve como objetivos isolar e selecionar linhagens de Pseudomonas sp. produtoras de biossurfatantes, e investigar a capacidade das culturas selecionadas em utilizar resíduos de óleos e gorduras como substratos alternativos para a produção destes compostos. As propriedades tensoativas e a caracterização dos biossurfatantes obtidos também foram avaliadas

\section{Material e métodos}

\subsection{Isolamento de microrganismos}

Foram utilizados microrganismos isolados de amostras de solo oriundos de aterros de indústrias de óleos, abatedouros de aves e postos de gasolina. Inicialmente, $10 \mathrm{~g}$ de solo foram diluídos em $50 \mathrm{~mL}$ de água destilada estéril, e desta suspensão transferiu-se $1 \mathrm{~mL}$ para Erlenmeyer contendo $20 \mathrm{~mL}$ de caldo nutriente. $\mathrm{O}$ frasco foi incubado em mesa agitadora a $30{ }^{\circ} \mathrm{C}$ e $200 \mathrm{rpm}$ por 24 horas, e alíquotas de $0,1 \mathrm{~mL}$ do meio fermentado foram transferidas para placas de Petri contendo ágar nutriente. As colônias isoladas obtidas foram inoculadas em placas contendo Blue Agar (SIEGMUND; FRITZ, 1991) para a detecção de glicolipídios extracelulares; e para placas contendo o meio de King B. (KING; WARD; RANEY, 1954) utilizado para crescimento e deteç̧ão de pigmentos característicos de Pseudomonas spp. A linhagem Pseudomonas aeruginosa LBI produtora de ramnolipídios (BENINCASA et al., 2002) foi utilizada como controle positivo. Todos os microrganismos isolados foram estocados em caldo nutriente contendo $20 \%$ de glicerol e mantidos a $-20^{\circ} \mathrm{C}$.

\subsection{Produção de biotensoativos}

Os isolados selecionados foram testados quanto à capacidade de produzir biotensoativos; inicialmente testou-se o óleo de soja refinado e novo como fonte de carbono.

\section{Preparo do inóculo}

Partindo-se da cultura estoque de cada isolado selecionado, transferiu-se uma alçada para tubo contendo ágar nutriente incubando-o por 24 horas a $30^{\circ} \mathrm{C}$. Aproximadamente $3 \mathrm{~mL}$ de água destilada estéril foram adicionados à cultura obtendo-se uma suspensão bacteriana cuja densidade óptica $(610 \mathrm{~nm})$ foi ajustada para 0,65 , correspondendo a aproximadamente $10^{8}$ UFC. $\mathrm{mL}^{-1} ; 1 \mathrm{~mL}$ desta suspensão foi inoculada em frascos Erlenmeyer de $250 \mathrm{~mL}$ contendo $50 \mathrm{~mL}$ de meio de cultivo salino descrito por Robert et al. (1989), contendo (g.L $\left.\mathrm{L}^{-1}\right)$ : $\mathrm{NaNO}_{3}, 4.0 ; \mathrm{K}_{2} \mathrm{HPO}_{4}, 1.0 ; \mathrm{KH}_{2} \mathrm{PO}_{4}, 0.5 ; \mathrm{MgSO}_{4} .7 \mathrm{H}_{2} \mathrm{O}, 0.5 ; \mathrm{KCl}$, $0.1 ; \mathrm{FeSO}_{4} .7 \mathrm{H}_{2} \mathrm{O}, 0.01 ; \mathrm{CaCl}_{2}, 0.01$; extrato de levedura, $0.01 \mathrm{e}$ 0.05 mL.L ${ }^{-1}$ de uma solução de elementos traços: $\mathrm{B}(0,026 \%)$, $\mathrm{Cu}(0,05 \%), \mathrm{Mn}(0,05 \%), \mathrm{Mo}(0,06 \%)$ e Zn (0,07\%), suplementados com $2 \%\left({\left.\mathrm{p} . \mathrm{v}^{-1}\right)}\right.$ de óleo de soja como fonte de carbono. $\mathrm{O}$ inóculo foi incubado por 24 horas, $30^{\circ} \mathrm{C}$ e $200 \mathrm{rpm}$ em mesa agitadora (New Brunswick, USA).
Produção de biotensoativos em óleo de soja

Foi transferido $1 \mathrm{~mL}$ do inóculo para frascos Erlenmeyer de $125 \mathrm{~mL}$, contendo $25 \mathrm{~mL}$ do meio salino, adicionado de $2 \%$ de óleo de soja incubando-se por 120 horas, $30^{\circ} \mathrm{C}$ e $200 \mathrm{rpm}$ em mesa agitadora (New Brunswick, USA). $\mathrm{O}$ pH inicial do meio foi ajustado para $6,8-6,9$.

\section{Produção em substratos alternativos}

Os testes com resíduos foram realizados apenas com os isolados que mostraram capacidade de reduzir a tensão superficial do meio contendo óleo de soja para valores abaixo de $40 \mathrm{mN} / \mathrm{m}$. Os ensaios foram realizados conforme descrito acima utilizando-se resíduos de borra de soja, óleo de fritura, gordura de frango e gordura vegetal hidrogenada que foram adicionados ao meio de produção na concentração de $2 \%\left(p \cdot v^{-1}\right)$. A borra de soja consiste em um resíduo do refino do óleo de soja, resultante do processo de neutralização, que contém quantidade considerável de óleo, podendo ser utilizada como fonte de carbono para a produção de biossurfatantes (NITSCHKE et al., 2005).

\subsection{Determinações analíticas}

Amostras do meio foram retiradas ao final de 120 horas de cultivo ou em intervalos de tempo pré-estabelecidos (ensaios de cinética), sendo submetidas à análise. Para a determinação de biomassa celular foi utilizada alíquota da amostra contendo as células.

O restante da amostra foi centrifugado a $10.000 \mathrm{rpm}$ por 20 minutos e o sobrenadante foi submetido a medidas de tensão superficial, atividade emulsificante e concentração de ramnolipídios.

\section{Determinação da biomassa celular}

O crescimento celular foi acompanhado através da medida da concentração de proteínas presentes no meio de cultivo, segundo o método de Lowry et al. (1951).

\section{Quantificação de ramnolipídios (biossurfatante)}

A concentração de ramnose foi determinada utilizando-se o método de Chandrasekaran e Bemiller (1980). A conversão do valor de ramnose para ramnolipídio foi calculada através da multiplicação do valor da ramnose por 3 (ITOH; HONDA; TOMOTA, 1971).

\section{Determinação da tensão superficial}

O monitoramento da produção de biotensoativos foi realizado medindo-se a tensão superficial, segundo o método do anel de DE NÖUY (ZAJIC; SEFFENS, 1984) e utilizando-se um Tensiômetro Krüss (modelo K12).

\section{Atividade emulsificante}

Em um tubo de ensaio com tampa rosca adicionou-se $4 \mathrm{~mL}$ do meio obtido após 120 horas de cultivo e $6 \mathrm{~mL}$ do composto hidrofóbico a ser testado: querosene, benzeno ou óleo de soja. 
O tubo foi fechado e agitado vigorosamente em agitador vortex por 2 minutos, deixando-se em repouso por 24 horas. A atividade emulsificante $\left(\mathrm{E}_{24}\right)$ foi calculada como: (altura da camada emulsionada/altura total de líquido) x 100 (IQBAL; KHALI; MALIK, 1995).

Os experimentos foram conduzidos em triplicata e as barras de erro (quando mostradas) representam o desvio padrão.

\section{Resultados e discussão}

Dezoito microrganismos foram isolados e submetidos ao teste descrito por Siegmund e Fritz (1991) para a detecção de secreção de glicolipídios. Dos 18 isolados obtidos, 13 mostraram resultados positivos ao teste de Blue Agar, indicando produção de glicolipídios aniônicos. Inicialmente os 13 isolados foram testados, visando determinar o potencial para a produção de biotensoativos em meio contendo óleo de soja como fonte única de carbono. Partindo-se de uma tensão superficial inicial de $60 \mathrm{mN} / \mathrm{m}$, verificou-se a capacidade dos microrganismos em reduzir a tensão superficial do meio. Dos 13 isolados testados, 2 (LMI 6c e LMI 7a) reduziram a tensão superficial para $32 \mathrm{mN} / \mathrm{m}$ (Figura 1). Segundo Haba et al. (2000), um produtor potencial de biossurfatante deve ser capaz de reduzir a tensão superficial do meio para valores abaixo de $40 \mathrm{mN} / \mathrm{m}$, portanto os dois isolados foram selecionados para a continuidade dos estudos.

Os isolados selecionados foram obtidos de amostras de solo contaminadas com óleo diesel, e no meio King, Ward e Raney (1954) observou-se a produção de pigmentos característicos de Pseudomonas spp. Posteriormente estes isolados foram classificados como pertencentes ao gênero Pseudomonas sp. e designados como LMI 6c e LMI 7a.

Os dados obtidos da produção de ramnolipídios nos diferentes substratos após 120 horas de cultivo são mostrados na Tabela 1. Pseudomonas sp. LMI 6c e 7a, assim como a linhagem Pseudomonas aeruginosa LBI foram capazes de utilizar os resíduos testados e sintetizar o biotensoativo, sendo que a maior concentração de ramnolipídios foi obtida quando a borra de soja foi utilizada como substrato alternativo.

Em relação ao $\mathrm{pH}$, observou-se variação entre 5,7 a 8,6 e uma tendência para valores finais superiores a 8,0 quando as gorduras foram utilizadas como substratos. $\mathrm{O}$ maior aumento de biomassa celular (teor de proteína) foi observado para o isolado LMI 7a, sugerindo sua maior adaptação aos substratos propostos, se comparado aos outros microrganismos. A produção de ramnolipídios atingiu 9,69 g.L. $\mathrm{L}^{-1}$ quando o isolado LMI $6 \mathrm{c}$ foi cultivado em borra de soja e 7,73 g.L.-1 quando LMI 7a cresceu em óleo de fritura como fonte de carbono. Também se observa que a produção de ramnolipídios utilizando resíduos de gordura foi inferior à produção em resíduos de óleos (Tabela 1). Em comparação com a linhagem LBI (considerada padrão para a produção de ramnolipídios) os isolados LMI 6c e LMI 7a geraram concentrações de biotensoativo superiores na maioria dos resíduos testados. A tensão superficial final do meio de cultura nos substratos borra de soja, óleo de fritura e gordura de frango

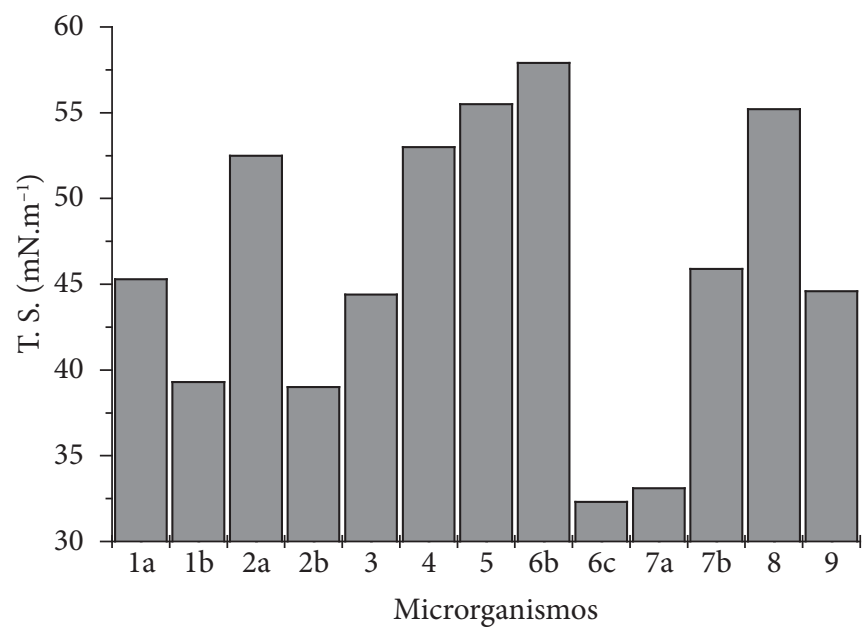

Figura 1. Seleção de microrganismos produtores de biotensoativos.

Tabela 1. Parâmetros da produção de ramnolipídios pelos isolados LMI 6c, LMI 7a e por P. aeruginosa LBI após 120 horas de cultivo nos diferentes resíduos oleosos testados.

\begin{tabular}{|c|c|c|c|c|c|}
\hline \multirow[t]{2}{*}{ Microrganismos } & \multicolumn{4}{|c|}{ Substratos } & \multirow[t]{2}{*}{ Parâmetros } \\
\hline & Óleo soja usado & Borra de soja & Gordura de frango & Gordura vegetal & \\
\hline \multirow[t]{4}{*}{ LBI } & 1,69 & 1,67 & 1,67 & 1,85 & Proteína $\left(\mathrm{g} \cdot \mathrm{L}^{-1}\right)$ \\
\hline & 5,09 & 7,52 & 3,9 & 1,71 & $\mathrm{RL}^{1}\left(\mathrm{~g} \cdot \mathrm{L}^{-1}\right)$ \\
\hline & 32,6 & 33,2 & 32,3 & 35 & $\mathrm{TS}^{2}(\mathrm{mN} / \mathrm{m})$ \\
\hline & 7,23 & 7,72 & 8,46 & 8,64 & $\mathrm{pH}$ \\
\hline \multirow[t]{4}{*}{ LMI $6 c$} & 1,62 & 1,57 & 0,73 & 1,44 & Proteína (g. $\left.\mathrm{L}^{-1}\right)$ \\
\hline & 6,1 & 9,69 & 3,04 & 2,03 & RL (g. $\left.\mathrm{L}^{-1}\right)$ \\
\hline & 31 & 31,9 & 34 & 35 & $\mathrm{TS}(\mathrm{mN} / \mathrm{m})$ \\
\hline & 5,7 & 7,01 & 8,43 & 8,25 & $\mathrm{pH}$ \\
\hline \multirow[t]{4}{*}{ LMI 7a } & 2,1 & 1,86 & 2,74 & 2,07 & Proteína $\left(\mathrm{g} \cdot \mathrm{L}^{-1}\right)$ \\
\hline & 7,73 & 7,49 & 4,88 & 1,87 & RL (g. $\left.\mathrm{L}^{-1}\right)$ \\
\hline & 34 & 31,9 & 34,1 & 35 & $\mathrm{TS}(\mathrm{mN} / \mathrm{m})$ \\
\hline & 8,22 & 7,03 & 8,31 & 8,5 & $\mathrm{pH}$ \\
\hline
\end{tabular}

${ }^{1} \mathrm{RL}$ : ramnolipídios; $\mathrm{e}^{2} \mathrm{TS}$ : tensão superficial. 
variou entre 31 a $33 \mathrm{mN} / \mathrm{m}$, já a gordura vegetal hidrogenada variou de 35 a $37 \mathrm{mN} / \mathrm{m}$. Estes resultados são similares aos descritos para P. aeruginosa LBI (BENINCASA et al., 2002; NITSCHKE et al., 2005), P. aeruginosa AT10 (ABALOS et al., 2001) e P. aeruginosa BS2 (DUBEY; JUWAKAR, 2001).

Haba et al. (2000) selecionaram 9 isolados de Pseudomonas sp. capazes de crescer em meio contendo óleo de fritura (óleos de girassol e oliva) e acumular compostos tensoativos; sendo que a tensão superficial final do meio variou entre 34 a $36 \mathrm{mN} / \mathrm{m}$. $\mathrm{O}$ isolado $P$. aeruginosa 47T2 mostrou uma produção final de ramnolipídios de 2,7 g.L $\mathrm{L}^{-1}$ Já Costa et al. (2006) obtiveram uma concentração final de 9,9 e 9,2 g. $\mathrm{L}^{-1}$ de ramnolipídios quando $P$. aeruginosa LBI cresceu em óleos de castanha-do-pará e maracujá, respectivamente.

A cinética de produção de ramnolipídios pelos isolados LMI 6c e LMI 7a em óleo de soja usado é mostrada nas Figuras 2 e 3. Nota-se que a biomassa celular aumentou durante
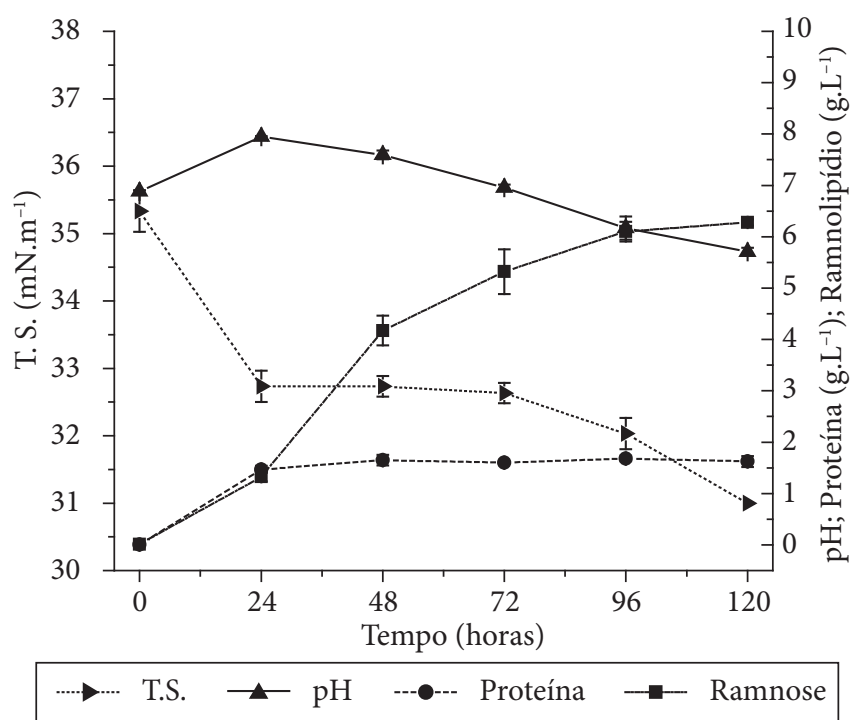

Figura 2. Cinética da produção de ramnolipídios por Pseudomonas sp. LMI 6c usando óleo de soja usado.

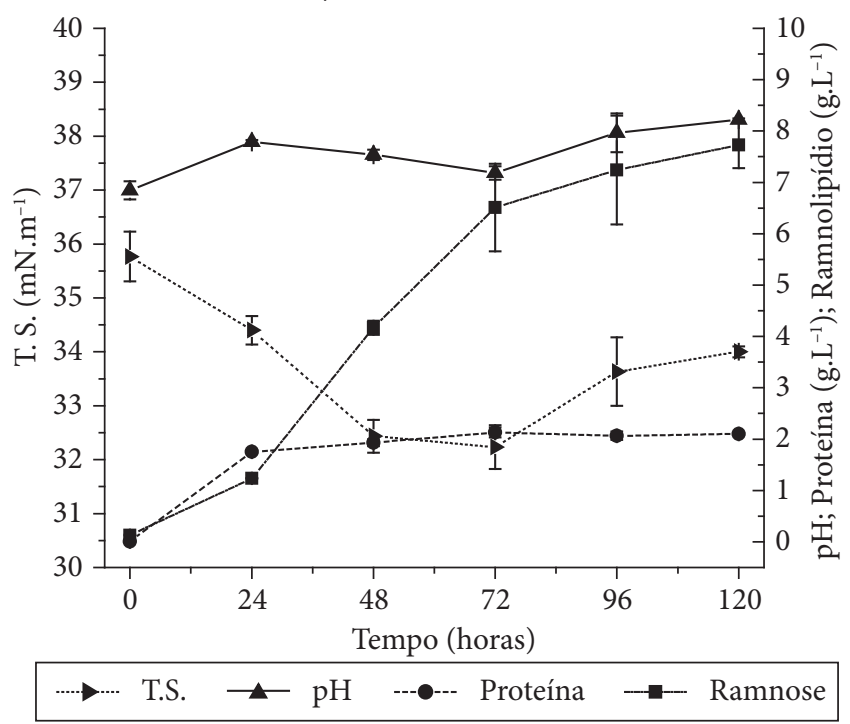

Figura 3. Cinética da produção de ramnolipídios por Pseudomonas sp. LMI 7a utilizando óleo de soja usado. as primeiras 24 horas de cultivo e posteriormente se manteve constante, sugerindo que os microrganismos se mantiveram em fase estacionária. $\mathrm{O}$ maior incremento da produção de ramnolipídios ocorreu entre 24 e 96 horas, demonstrando que a produção não está associada ao crescimento celular e que o produto se acumula como um metabólico secundário. Em função do acúmulo de biotensoativo no meio também se observa queda na tensão superficial.

A Figura 4 mostra os valores da atividade emulsificante $\left(\mathrm{E}_{24}\right)$ obtidos pelos ramnolipídios de Pseudomonas LMI 6c e LMI 7a contra querosene, benzeno e óleo de soja após 24 horas. Os biotensoativos produzidos em óleo usado (OU) demonstraram maior capacidade emulsionante contra óleo de soja e benzeno do que os biotensoativos produzidos em borra de soja (BS). As emulsões formadas foram do tipo óleo-água $(\mathrm{O} / \mathrm{A})$ e água-óleo (A/O). A estabilidade contra óleo de soja foi de 6 dias e contra querosene e benzeno de 30 dias. Estes resultados revelam o excelente potencial destes compostos para uso na biorremediação de poluentes e na indústria de alimentos e cosmética como agentes emulsionantes e solubilizantes.

O tipo da fonte de carbono afetou as propriedades e a concentração final dos ramnolipídios produzidos, ou seja, a produção em resíduos de gorduras foi inferior à produção em resíduos de óleos, e as propriedades como tensão superficial e atividade emulsificante também variaram. Estas diferenças podem estar associadas à composição de triglicérides dos substratos utilizados (VATER, 1986) e à atividade da lipase microbiana (SHABTAI; DAYA-MISHNE, 1992) sobre estes substratos. Cabe ressaltar que também foram observadas diferenças na produção de ramnolipídios entre os microrganismos testados mesmo quando se utilizou o mesmo tipo de substrato. Diferenças na composição dos ramnolipídios produzidos também podem resultar em diferenças nas propriedades biotensoativas (NITSCHKE et al., 2005).

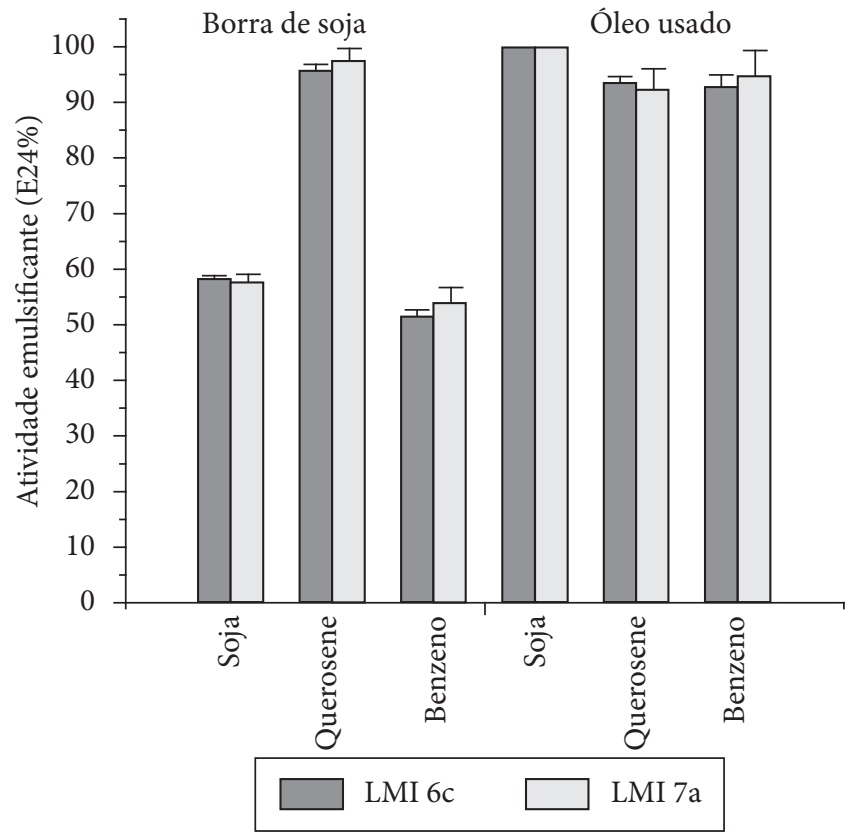

Figura 4. Atividade emulsificante dos biotensoativos produzidos pelos isolados LMI 6c e LMI 7a em meio contendo borra de soja e óleo usado frente a óleo de soja, querosene e benzeno. 
Mesmo com a menor concentração de ramnolipídios obtida, quando os isolados LMI 6c e LMI 7a cresceram em resíduos de gorduras, os resultados são semelhantes aos dados relatados na literatura (ABALOS et al., 2001; HABA et al., 2000; NITSCHKE et al., 2005; NITSCHKE; COSTA, 2006), sugerindo que estes substratos podem ser utilizados, desde que se busque maior adaptação dos isolados obtidos ou de novos microrganismos a estes resíduos.

Nitschke et al. (2005) utilizaram fontes hidrofílicas (glicerol e glicose) e hidrofóbicas (borra de soja, óleo de fritura e gordura de frango) como fonte de carbono para a produção de ramnolipídios, e verificaram que os substratos oleosos apresentaram uma produção de ramnolipídios $64 \%$ maior do que os substratos não oleosos. Assim sendo, este trabalho valorizou as fontes hidrofóbicas como fonte de carbono e mostrou resultados iguais ou superiores aos relatados na literatura (ABALOS et al., 2001; BENINCASA et al., 2002; COSTA et al., 2006; NITSCHKE et al., 2005; NITSCHKE; COSTA, 2007).

Os resíduos oleosos estudados são produzidos em grande quantidade pelas indústrias de processamento de óleos vegetais e alimentícias, sendo que a utilização destes resíduos poderá contribuir não somente com a redução dos custos de tratamento, mas também com a valorização econômica destes.

Considerando que o custo de produção é o maior problema para a expansão do mercado de biossurfatantes, a procura por substratos alternativos e o isolamento de novos microrganismos constituem uma estratégia para implementar a obtenção e o uso destas moléculas. Este trabalho mostrou o potencial de uso de resíduos de indústrias alimentícias como fonte de carbono na produção de biotensoativos, bem como o isolamento de dois novos microrganismos.

\section{Conclusão}

Os isolados selecionados, Pseudomonas sp. LMI 6c e LMI 7a, demonstraram capacidade para sintetizar ramnolipídios a partir de resíduos de óleos e gorduras como substratos alternativos. A borra de soja e o óleo de soja usado destacaram-se como fontes potenciais para o desenvolvimento do processo alternativo para produção de biotensoativos.

\section{Agradecimentos}

À Fundação de Amparo à Pesquisa do Estado de São Paulo (FAPESP), ao Conselho Nacional de Pesquisa (CNPq) e à empresa Cargill S.A., pela doação da borra de soja.

\section{Referências bibliográficas}

ABALOS, A. et al. Physicochemical and antimicrobial properties of new rhamnolipids produced by Pseudomonas aeruginosa AT10 from soybean oil refinery wastes. Langmuir, Washington, DC, v. 17, n. 5 p. 1367-1371, 2001.

BANAT, I. M.; MAKKAR, R. S.; CAMEOTRA, S. S. Potential commercial application of microbial surfactants. Appl. Microbiol. Biotechnol., Heidelberg, v. 53, n. 5, p. 495-508, 2000.

BENINCASA, M. et al. Rhamnolipid production by Pseudomonas aeruginosa LBI growing on soapstock as the sole carbon source. J. Food Eng., Meppel, v. 54, n. 4, p. 283-288, 2002.
CAMEOTRA, S. S.; MAKKAR, R. S. Synthesis of biosurfactants in extreme condictions. Appl. Microbiol. Biotechnol., (Heidelberg) v. 50 , n. 5 , p. 520-529, 1998.

CHANDRASENKARAN, E. V.; BEMILLER, J. N. Constituint analysis of glycosaminoglycans. In: Methods In Carbohydrate Chemistry, v. III, Academic Press, Nova York, p. 89-96, 1980.

COSTA, S. G. V. A. O. et al. Production of Pseudomonas aeruginosa LBI rhamnolipids following growth on Brazilian native oils. Process Biochemistry, Oxford, v. 41, n. 2, p. 483-488, 2006.

DESAI, J. D.; BANAT, I. M. Microbial production of surfactants and their commercial potential. Microbiol. Mol. Biol. Rev., Washington, DC, v. 61, n. 1, p. 47-64. 1997.

DUBEY, K.; JUWAKAR, A. Distillery and curd whey wastes as viable alternative sources for biosurfactant production. W. J. Microbiol. Biotechnol., Amsterdam, v. 17, n. 1, p. 61-69, 2001.

HABA, E. et al. Screening and production of rhamnolipids by Pseudomonas aeruginosa 47T2 NCBI 40044 from waste fryiong oils. J. Appl. Microbiol., London, v. 88, n. 3, p. 379-387, 2000.

IQBAL, S.; KHALI, Z. M.; MALIK, K. A. Enhanced biodegradation and emulsification of crude oil and hyperproduction of biosurfactants by a gamma ray induced mutant of Pseudomonas aeruginosa. Letters Appl. Microbiol., London, v. 21, n. 2, p. 176-179, 1995.

ITOH, S. et al. Rhamnolipids produced by Pseudomonas aeruginosa grown on n-paraffin. J. Antibiotics, Tokyo, v. 24, n. 12, p. 855-859, 1971.

KING, E. O.; WARD, M. K.; RANEY, D. E. Two simple media for the demonstration of pyocyanin and fluorescin. J. Laborat. Clinic. Medical, Milwaukee, v. 44, n. 3, p. 301-307, 1954.

LOWRY, O. H. et al. Protein measurement with the folin phenol reagent. J. Biolog. Chemistry, Rockville Pike, v. 193, n. 1, p. 265-275, 1951.

NITSCHKE, M. et al. Oil wastes as unconventional substrates for rhamnolipid biosurfactant production by Pseudomonas aeruginosa LBI. Biotechnol. Prog., Washington, DC, v. 21, n. 5, p. 1562-1566, 2005.

NITSCHKE, M.; COSTA, S. G. V. A. O.; CONTIERO, J. Rhamnolipid Surfactants: an update on the general aspects of these remarkable biomolecules. Biotechnol. Prog., Washington, DC, v. 21, n. 6, p. 1593-1600, 2005.

NITSCHKE, M.; COSTA, S. G. V. A. O. Biosurfactant in food industry. Trends in Food Science \& Technology, Oxford, v. 18, n. 5, p. 252-259, 2007.

ROBERT, M. et al. Effect of the carbon source on biosurfactant production by Pseudomonas aeruginosa 44T1. Biotechnol. Letters, Amsterdam, v. 1, n. 2, p. 871-874, 1989.

SHABTAI, Y.; DAYA-MISHNE, N. Production, purification, and properties of a lipase from a bacterium (Pseudomonas aeruginosa YS-7) capable of growing in water-restricted environments. Appl. Environ. Microbiol., Washington, DC, v. 58, n. 1, p. 174-180, 1992.

SIEGMUND, I.; FRITZ, W. New method for detecting rhamnolipids excreted by Pseudomonas species during growth on mineral agar. Biotechnol. Techniques, Amsterdam, v. 5, n. 4, p. 265-268, 1991.

VAN HAMME, J. D.; SINGH, A.; WARD, O. P. Physiological aspects. Part 1 in a series of papers devoted to surfactants in microbiology and biotechnology. Biotechnology Advances, Oxford, v. 24, n. 6, p. 604-620, 2006.

VATER, P. J. Lipopeptides in food applications. In; Kosaric N (ed) Biosurfactants- production, properties and applications. New York: Marcel Dekker 1986. p. 419-446.

ZAJIC, J. E.; SEFFENS, W. Biosurfactants. CRC Critical Reviews in Biotechnology, Boca Raton, v. 1, n. 2, p. 87-107, 1984. 